\title{
D escentralização, participação e esfera pública: reflexões sobre a literatura com base no caso de Teresina, Piauí
}

\author{
Washington Luís de Sousa Bonfim* \\ Marysol Alves de OliveIRA** \\ IrISMar Nascimento da SiLVA***
}

\begin{abstract}
R esumo: Este texto proarra refletir sobre questões relativas ao processo de descentralização de políticas públicas, com base em dadbs empíricos do município de Teresina (PI), ande se realizaram dois trabalhos de análise do funcionamento e da participação da sociedade civil nos conselhos gestores municipais de assistência social e da criança e adblescente. Os dados apontam para uma grande fragilidade da participação da sociedade civil em ambos os conselhos e, apesar de podermos dizer que, em pelo menos um caso, há deliberação, esta resume-se a tarefas burocráticas, tais como o credenciamento de entidades nãogovemamentais que estão pleiteandb títulos de filantropia, com pouco ou nenhum impacto sobre política pública municipal.
\end{abstract}

Palavras-chave: descentralização, políticas públicas, participação social, conselhos gestores.

Os dados iniciais ${ }^{1}$ aqui apresentados levamnos a considerar como a literatura tem tratado o fenômeno da descentralização, com base em uma indagação específica: em que medida a descentralização das políticas públicas, em contextos como o do município de Teresina, pode ajudar a mudar a real idade local, que pode ser brevemente descrita como de extrema

\footnotetext{
* Bacharel em Ciências Sociais pela UFPI, mestre em Ciências Políticas pela Iuperj e doutor em Ciências Políticas pela luperj. Professor da Universidade Federal do Piauí. Email: wbonfim@uol.com.br

** Bacharel em Ciências Sociais pela UFPI e mestre em Políticas Públicas pela UFPI. E-mail: oliveiramarysol@ hotmail.com

*** Bacharel em Ciências Sociais pela UFPI e mestranda em Sociologia pela UFC.E-mail: irismars@uol.com.br

1. Os dados apresentados foram coletados no contexto do projeto de pesquisa Novas Dinâmicas Institucionais? Descentralização e Participação Popular em Teresina, Piauí, que tem financiamento do CNPq.
}

pobreza, desigualdade social e clientelismo político?

Essa preocupação justifica-se de duas maneiras. Em primeiro lugar, al guns autores têm levantado questionamentos a respeito do consenso que se estabeleceu na sociedade brasileira quanto à necessidade e à positividade da descentralização como caminho de aprofundamento da democracia e, portanto, de mudança social no país. Em Stepan (2002), essa posição encontra uma formulação explícita, com um al erta sobre as condições nas quais o processo vem criando condições para maior concessão de poder e recursos às elites locais.

Em linha diversa, mas com a mesma reserva quanto à ef etividade da descentralização em certos contextos, Boschi (1999), comparando as experiências de Salvador e Belo Horizonte, faz um alerta também contundente, afirmando de maneira conclusiva: 
uma vez que parecem inscrever-se num processo de causação circular, práticas de governança têm tanto maior chance de vingar, quanto mais forte for o Estado e a própria sociedade civil. Em caso contrário, isto é, na dificuldade de sua generalização ao longo do espectro social, as práticas de governança e participação correm o risco de se constituírem em alternativas fadadas ao insucesso para os que delas mais necessitam: os desorganizados e destituídos de recursos. (1999, p. 683)

Souza (1996) com base na premissa de que o federalismo brasileiro sempre cumpriu um papel de amortização dos conflitos decorrentes das demandas de diversas elites, sendo um "meio para amortecer as enormes disparidades regionais" (1996, p. 104), observa que, por exemplo, em Salvador, al guns fatores políticos e econômicos demonstraram os limites do processo de descentralização, o mesmo acontecendo em outro município baiano de características bastante distintas da capital, Camaçari. N esse caso, chama atenção para o impacto do federalismo e a descentralização sobre as desigualdades sociais e regionais.

A mesma autora (2001) destacou quatro questões que considera importantes para entender as vicissitudes do federal ismo no $B$ rasil pós88: 1) analisando o papel duplo e contraditório das unidades subnacionais no contexto da federação, uma vez que têm de atender às demandas por serviços sociais, ao mesmo tempo em que constrangem os objetivos de política econômica do governo federal, constata que esse papel vem impedindo a criação de condições para mudanças no quadro das desigualdades sociais e regionais; 2) a heterogeneidade das condições com as quais o processo de descentralização vai se defrontar nos municípios brasileiros traz a constatação de que, em muitos deles, não há possibilidades de provimento de serviços; 3 ) quanto a estes, é preciso saber em que condições têm sido providos e como a situação de concentração de poder político nas subunidades nacionais cria constrangimentos ou incentivos de acesso, e, finalmente, 4) a agenda econômica do governo federal tem dois tipos de efeitos sobre o federalismo e a descentralização - o primeiro é relativo ao aumento da concentração econômica nos E stados mais desenvolvidos e o segundo diz respeito ao modo como os interesses paulistas são afetados por essa agenda.

A segunda justificativa para a pergunta sobre a relação entre o processo de descentralização e a mudança das condições sociais de municípios com as características da capital piauiense tem a ver com o "reconhecimento de que a atual onda de descentralização decorre precisamente desse processo de crise das instituições públicas. N esse sentido, rima com temas como 'reforma do Estado', ' diminuição dos gastos sociais', 'estado mínimo', etc." (N unes, 1996, p. 38, grifo do autor). N esse sentido, a citação vai contra 0 espírito em que se assentou a proposta de descentralização da Constituição de 1988 e coloca em debate questões que, de uma maneira ou de outra, se encontram muito presentes na literatura que hoje trata não apenas da descentralização propriamente dita, como do desenvolvimento.

Para essa literatura, o conceito de capital social, com suas implicações para a questão do desempenho institucional, organiza o conjunto de possibilidades de reversão de situações em que prevalecem relações políticas de características verticais, assi métricas e hierárquicas. $\mathrm{Na}$ tentativa de fugir da armadilha "genética", também chamada culturalista (A bu-El-Haj, 1999), da explicação de Putnam (1996), alguns autores têm levantado a possibilidade de que determinados arranjos entre Estado e sociedade civil podem contribuir na própria criação de capital social (Evans, 1996a, 1996b; Fox, 1994, 1996) de dinâmicas virtuosas de governo (Tendler, 1997). A s instituições e a partici pação política seriam, assim, elementos efetivos de promoção de mudança social.

Da mesma maneira, partindo da suposição de que a descentralização traz para perto da população o governo e, assim, viabiliza maior eficácia na prestação dos serviços e accountability quanto às ações governamentais, muitos autores têm procurado analisar as condições de participação política abertas pelo processo no B rasil, seja através da experiência dos consel hos gestores, seja através das várias experiências de orçamento participativo (Santos, 2002; Dagnino, 2002; Dias, 2002; Coelho et alli, 2002). Nesse caso, existe uma certa aposta de que a tradição autoritária e burocrática do Estado 
brasileiro pode ser vencida e de que a política social pode funcionar como elemento de construção de uma sociedade mais justa. A informar esse registro está o conceito de democracia deliberativa, que "propiciaria uma ampliação do espaço público, com a possibilidade de discussão aberta e deliberação acerca de políticas públicas e a democratização do processo decisório, além da possibilidade de controle social" (Coelho et alli, 2002, p. 5).

Para retomar o ponto da interseção entre a discussão da descentral ização e o tema da globalização, que é afinal de contas a que se refere Nunes (1996) quando remete à disjuntiva entre desenvolvimento desigual eassimétrico, no sentido econômico, e as demandas cada vez maiores pelo aprofundamento da igualização, o autor argumenta em prol da necessidade de se dar resposta a al gumas questões difíceis. Em primeiro lugar, seria importante o reconhecimento de que, da assimetria e incongruência entre poderes público e privado, a ênfase no reforço do poder local viria em favor do aumento do desequilíbrio entre democracia e desenvolvimento desigual. Em segundo lugar, estaria a tarefa de "repensar o sistema representativo, na tentativa de pavimentar 0 atual fosso entre representantes e representados" (1996, p. 38). Final mente, cabe uma reflexão sobre a difusão e a capilaridade dos efeitos do poder nas dimensões territoriais, para que se possa pensar como realmente funcionam os processos de descentralização e não continuar a imaginar como deveriam ser.

O bserva-se, então, que há inúmeros desafios a serem enfrentados quando se trata de entender o modo como as políticas públicas no B rasil vêm se produzindo no contexto do "novo" federal ismo implantado pós-88. Os diagnósticos mais compreensivos e recentes (A rretche, 2000) indicam a necessidade de pensar a heterogeneidade de ritmos e configuração do processo por entre as várias áreas e, por outro lado, sugerem a necessidade de entender as várias reali dades subnacionais, tanto do ponto de vista da política social, quanto dos seus impactos fiscais (Souza, 2001).

Duas preocupações aparecem, então, de maneira mais saliente, no que se refere à reflexão que se fará neste texto. A primeira tem a ver com o ponto levantado por Stepan (2002) quanto à validade do que chama de novo "Consenso de Washington" em favor da descentral ização, especialmente no caso brasileiro, que qualifica como um caso extremo de restrição do demos entre as várias experiências federais do mundo (1999).

Depois, há o alerta quanto as restrições que esse "novo" federalismo impõe ao problema das desigualdades sociais e regionais do país. Souza (1996, 1998, 1999 e 2001) está entre os autores que mais dão ênfase a esse aspecto específico, chamando atenção para os problemas decorrentes de vários tipos de fatores: a) a agenda econômica do governo federal nos últimos oito anos; b) o contraste entre fragmentação do poder político na esfera federativa e as condições de concentração em enorme quantidade desubunidades; c) o impacto da descentral ização de recursos sobre o provimento de serviços sociais e, também, as condições em que puderam ser realizados esforços de ajuste fiscal nas subunidades, d) e a recentralização que vem sendo promovida pelo governo federal, por meio de inúmeros mecanismos institucionais, como 0 aumento de contribuições e impostos cuja receita é exclusiva da União, o corte de despesas em algumas áreas, com pressão para aumento do investimento por parte das subunidades e também mecanismos como o Fundo de Estabilização Fiscal (FEF) e a L ei de ResponsabilidadeFiscal (LRF).

Nesse sentido, este texto anota problemas concretos que puderam ser percebidos no contexto do município de Teresina. M uitos deles, como se verá, registram-se em vários outros municípios do país, fazendo parte de um conjunto de dilemas já bastante discutido em diversos estudos de caso sobre a descentralização e a experiência dos conselhos gestores.

De qualquer modo, em que pese a necessidade de começar a dar conteúdo concreto a propostas comparativas de pesquisa, está-se aqui fazendo uma tentativa no sentido de se aquilatar o impacto da descentral ização em ambientes em que a possibilidade de captura da participação por interesses clientelistas e, por outro lado, os dilemas de representatividade da sociedade civil e de sua capacitação para a tarefa de intervenção no cotidiano das discussões dos conselhos são significativamente aumentados pelos fatores 
sociais e econômicos que informam a institucionalização dessa participação.

Concretamente, dada a exigüidade de casos aqui analisados, apenas dois, e a complexidade das variáveis que podem ajudar a compor o diagnóstico sobre as perspectivas da descentralização como elemento condutivo à mudança social em Teresina, não é possível neste trabalho adiantar conclusões muito profundas, senão estabelecer os parâmetros com base nos quais, a longo prazo, se pode dar concretude a respostas mais convincentes sobre se a descentral ização na capital piauiense tem ajudado aos que mais deveriam se beneficiar da ação do Estado ou se, por outro lado, tem em verdade funcionado como um elemento adicional na concentração de recursos e serviços nas mãos daqueles que, melhor organizados, restringem o acesso das populações mais carentes aos serviços sociais.

Para realizar esse objetivo, o trabal ho está estruturado em três partes. A primeira traz uma breve descrição do município de Teresina, principal mente do ponto de vista das condições políticas que se estabeleceram na capital durante a década de 1990. Depois, são apresentados os dados sobre a pesquisa realizada junto aos consel hos municipais de assistência social e da criança e do adolescente. Final mente, fazemos algumas breves conclusões.

1. Teresina e a descentralização das políticas públicas

Teresina é a capital do estado do Piauí, sua cidade mais importantee, em 2000, tinha 715.360 habitantes, com uma taxa de alfabetização de $86,8 \%$ (IB GE, 2000). Sua economia está baseada fundamental mente no setor de serviços, contando com a forte presença do setor público, em seus três níveis, como um dos principais empregadores e elementos dinâmicos da vida local. Como exemplo, no poder público municipal, nas suas administrações direta eindireta, estão empregados 10.167 funcionários² (BIM /IB GE, 2000).

2. Existem dados de estudos locais que indicam que, no Piauí, o conjunto de recursos que aportam à economia na forma de transferências federais, em todas as suas variantes, representa pouco mais de $40 \%$ de todos os recursos que são movimentados anualmente no estado (Veloso Filho, 2001; M edeiros, 2001).
Do ponto de vista do processo de descentralização, em praticamente todas as áreas estão constituídos os consel hos gestores, com destaque para os setores de educação, assistência social, criança e adolescente, habitação e saúde, muito embora não existam os consel hos relativos à administração do fundo público municipal na grande maioria das áreas de intervenção.

De maneira significativa, a partir do ano de 1997 adotou-se uma experiência de orçamento participativo, conhecida local mente como Orçamento Popular, que vem funcionando desde então. Entre as dificuldades principais de seu funcionamento, está o fato de uma certa deslegitimação da experiência, em virtude da incapacidade da prefeitura local de finalizar as obras e investimentos previstos nas várias versões já aprovadas até aqui.

Outra questão importante para a caracterização inicial do município tem relação com a infra-estrutura urbana disponível, que conta com uma pavimentação de vias públicas de cerca de $80 \%$ e uma cobertura de iluminação de $90 \%$ (BIM , IBGE, 2000). Ressal te-se ainda que, desde o final da década de 1980, a cidade vem passando por um processo de forte expansão populacional, decorrente em grande parte de fluxos migratórios do interior do estado. Formouse, dessa maneira, um cinturão de favelas e invasões de áreas públicas e privadas que vêm obrigando o poder público municipal a intervir cada vez mais freqüentemente na questão, orientando parte de seus recursos de investimento na criação de infra-estrutura para essas localidades, inclusive através de programas federais, como o Vila-Bairro, do BNDES.

Economicamente, como dissemos inicialmente, o setor de serviços é o mais importante, com destaque especial para a área de medicina especializada, que constitui pólo atrator de clientela médica de três estados próximos: M aranhão, Tocantins e Pará. Segundo dados oficiais da Prefeitura M unicipal de Teresina, 0 setor movimentou, em 2000, cerca de R \$240 milhões, correspondentes a $5,5 \%$ do PIB municipal. ${ }^{3}$

3. Segundo dados de 1996, o PIB do município estava situado em cerca de US\$2,3 milhões, enquanto o PIB per capita era de US\$3,6 mil dólares (Piauí, Informações M unicipais, Cepro, 2000). 
0 eleitorado teresinense, em 2000 , segundo os dados do Tribunal Superior Eleitoral, era de 394.605 eleitores, dos quais $54,6 \%$ eram mulheres. Note-se também que pouco mais de $48 \%$ do el eitorado estava situado na faixa etária dos 18 aos 34 anos. Politicamente, a prefeitura vem sendo dirigida pelo Partido da Social Democracia B rasileira (PSDB) desde 0 ano de 1992, quando foi eleito Wall Ferraz, um professor universitário, de características políticas contraditórias, ${ }^{4}$ que construiu uma imagem muito forte na cidade baseada na idéia de que a prefeitura deveria servir às populações mais carentes, tendo-se notabilizado como uma das mais carismáticas figuras políticas estaduais.

Tendo fal ecido durante o mandato, o cargo foi assumido pelo então vice-prefeito que, além de manter as características político-administrativas básicas já implementadas, conseguiu eleger o seu sucessor, um jovem de 34 anos, economista, que havia sido secretário municipal de Finanças no mandato de 1993 a 1996. Sua primeira eleição, no ano de 1996, foi fruto de um processo difícil de convencimento do eleitorado de que 0 então candidato era herdeiro do model 0 administrativo adotado por Wall Ferraz. Para a construção dessa imagem, todos os recursos foram utilizados, mas a posição do funcionalismo municipal nas eleições teve papel crucial, uma vez que temia as conseqüências da el eição do principal opositor, um líder político tradicional no estado, ex-governador por duas vezes: A lberto Tavares Silva (PMDB), com fama justificada de mau pagador. ${ }^{5}$

Durante o governo, o novo prefeito conseguiu estabelecer uma linha de ação que, aos olhos da população, tornou-se semel hante ao projeto político do início da década, o que veio a facilitar sua reel eição em 2000 , ainda no primeiro turno,

\footnotetext{
4. Em entrevista realizada com o atual prefeito da cidade, que foi trazido à administração pública por Wall Ferraz, Firmino Filho (PSDB) definiu-o como um político de características populistas que, apesar disso, procurava aliar suas propostas a um padrão de excelência burocrática. Talvez fosse mais correto interpretá-lo como um político carismático, que mantinha profundas relações com a população mais pobre da capital, mas que, no entanto, jamais teve liderança expressiva no estado como um todo. Quando de sua morte, Teresina presenciou uma de suas maiores manifestações populares.
}

5. O lema da campanha do candidato peessedebista no segundo turno foi o sugestivo: "Quem atrasa, não adianta". em aliança com o PMDB, que governava o estado e indicou o candidato a vice, um filho do agora senador A Iberto Silva.

Essa caracterização inicial importa do ponto de vista de nosso argumento em dois sentidos básicos. Primeiramente, nas palavras do próprio prefeito de Teresina, Firmino Filho (PSDB), a administração peessedebista da capital é descrita como fundada na lógica de dar sentido burocrático a uma proposta política que, em suas raízes, tinha um compromisso, segundo ele, "populista", de levar à periferia da cidade equipamentos públicos que promovessem a melhoria de vida da população.

Nesse caso, em sua concepção, o "populismo" decorreria de uma aposta em um perfil administrativo que visa privilegiar os bairros mais pobres da cidade, do ponto de vista da ação municipal. No entanto, tal preocupação não está ancorada em um propósito de ver representadas propostas políticas advindas dos setores organizados da vida popular. A o contrário, de certa maneira, ao longo da última década, foi marcada por uma série de movimentos associativos e uma estrutura de representação de características clientel istas fortemente ligadas à prefeitura.

A lém disso, outro componente do perfil de ação da Prefeitura M unicipal de Teresina, na última década, tem como característica uma espécie de varejo, pois não é possível identificar grandes obras que marquem a atuação do executivo municipal; ao contrário, estabelecese um conjunto de pequenas intervenções no equipamento urbano, na forma de cal çamento, construção de postos de saúde, centros comunitários, creches e os chamados escolões, que dão assistência aos estudantes em período integral. ${ }^{6}$

Finalmente, 0 aspecto burocrático para 0 qual o prefeito chama atenção pode ser identificado em tipos distintos de iniciativa. Por um lado, a prefeitura tem investido recursos na

\footnotetext{
6. U ma crítica sempre trazida à tona para atacar essas administrações é relativa ao fato de que sua ação na área de regularização de terrenos invadidos e urbanização de vilas e favelas deu lugar a uma "indústria da invasão", que induziu a população pobre do interior do estado a migrar para a capital. Existem alguns trabalhos locais a esse respeito, alguns levantando teses controvertidas relativas a uma expansão dessas ocupações em função do aumento da pobreza em certos setores da população já residente no município.
} 
criação de uma base de informações geográficas (SIG), que deverá servir à tarefa de estruturar o setor de planejamento, com base em uma visão integrada da administração local. N esse sentido, além da constituição da base de dados física, têm-se desenvolvido projetos específicos, que visam à integração dessa base inicial a outras bases de dados sobre problemas diversos relativos a saúde, educação, sistema de transportes, cal çamento e saneamento da cidade. Foi criado também um fórum de discussão de longo prazo acerca dos destinos da cidade, a chamada A genda Teresina 2015.

Em segundo lugar, com recursos de agências internacionais, está em curso um programa de modernização da arrecadação tributária da capital, com foco principal localizado no recadastramento de unidades prediais, que deverá atualizar a base sobre a qual hoje se faz a cobrança do Imposto Predial Territorial U rbano (IPTU), que é de 1981.

Em terceiro, ainda no sentido da intervenção burocrática desses governos, está o tratamento dado ao funcionalismo municipal, que, em contraste com o que aconteceu com o poder público estadual no mesmo período, sempre recebeu seus proventos em dia, apesar de os reajustes terem se dado, segundo o sindicato da categoria, em patamar inferior aos níveis inflacionários verificados durante os últimos oito anos.

Ressalte-se que, até 0 ano de 2004, a liderança peessedebista da capital conseguiu aglutinar um conjunto de forças de centroesquerda, ligadas a partidos como o Partido Comunista do Brasil (PC do B) e o Partido Democrático Trabal hista (PDT). 0 atual prefeito disputou a eleição de 2000 tendo como principal adversário o candidato petista, o então deputado federal Wellington Dias, e os principais partidos do espectro da direita política, incluindo 0 Partido da Frente Liberal (PFL), o mais forte deles no Estado que teve votação pouco expressiva, mudando de candidato ainda durante 0 pleito. $^{7}$

7. A pós a cassação do ex-governador M oraes Souza (PM DB) e de seu vice Osmar Júnior ( $P C$ do $B$ ), pelo Tribunal Superior Eleitoral (TSE), em 6 de novembro de 2001, o quadro político transformou-se radicalmente. Para as eleições de 2002, o PSDB aliou-se ao PFL, indicando o candidato a
Essas características contraditórias que unem a um só tempo carisma, clientelismo e viés administrativo burocrático vêm orientando 0 processo de descentralização no município, que tem avançado, como de resto em todo o país, segundo ritmos diferenciados, que dependem da área de política envolvida, das condições institucionais e das pressões dos grupos com interesse na questão. A pesar de a pesquisa ter avançado apenas na questão dos conselhos ligados às políticas sociais, muito especialmente os que se vinculam às políticas voltadas à população de crianças e adolescentes e à assistência, existe um histórico razoável de experiências nas áreas da saúde e de educação.

No que tange aos propósitos deste trabalho, cabe discorrer brevemente sobre pesquisas realizadas quanto ao aspecto da participação da sociedade civil nos consel hos gestores das áreas da criança e do adolescente e de assistência social. Porém, é oportuna uma pequena digressão.

Estamos tomando aqui a experiência dos consel hos gestores e, muito especialmente, a questão da participação popular nessas instituições com base em dois raciocínios iniciais. Primeiramente, a literatura tem dado enorme ênfase ao papel da participação política nesses consel hos como meio para que se possa, ainda que de maneira indireta, ter parâmetros para a interpretação das bases do processo de aprofundamento da democracia brasileira e, também, da questão da inclusão dos movimentos sociais no processo decisório sobre as políticas públicas no país, o que contribuiria para a melhoria da eficácia ea transparência dos serviços prestados pelo poder público, bem como para a ampliação da esfera pública municipal (Boschi, 1999; Gohn, 2000, 2001; B ravo \& Pereira, 2001; Teixeira, 2001; Dagnino, 2002).

Depois, pareceu-nos razoável trabalhar com a hipótese inicial de que a participação que se

vice na chapa do agora governador $\mathrm{H}$ ugo $\mathrm{N}$ apoleão, que busca a reeleição. O PM DB lançou candidato próprio, após várias tentativas de acordo com o PSDB, inviabilizadas por sua profunda crise, decorrente do apoio de algumas lideranças importantes ao novo governo. Os partidos de esquerda reaglutinaram suas forças para lançar a candidatura de Wellington Dias (PT) ao governo do estado, tendo como vice em sua chapa o ex-vice-governador cassado, do PC do $B$. Integra ainda a coligação o Partido Liberal (PL), seguindo a orientação nacional da Executiva petista. 
efetiva nesses espaços e o modo de relacionamento das administrações municipais com os consel hos poderiam funcionar como um indicador das possibilidades de mudança social ef etiva na sociedade brasileira contemporânea, e, éóbvio, teresinense, uma vez que, em acordo com as idéias de ampliação da esfera pública e de constituição da chamada democracia deliberativa, fundada na noção mais geral da democracia associativa,

an important feature of organizations generally, and parties in particular, is that they provide a means through which individuals and groups who lack the "natural" advantage of wealth can overcome the political disadvantages that follow on the lack. Thus the can help to overcome the inequalities in deliberative arenas that result from material inequality. (Cohen, 1997, p. 86)

Como já sugerimos na introdução deste texto, as observações empíricas a respeito dos conselhos que analisamos e as preocupações levantadas pela literatura, quanto aos efeitos da descentralização em ambientes marcados por profundas desigualdades sociais e regionais, têm nos levado a redirecionar o enfoque do trabal ho no sentido de entender se, ao invés de efeitos benéficos de ampliação da esfera pública e participação da população, esses mecanismos não têm sido capturados por grupos bem organizados, ou simplesmente cumprido uma agenda formal, destituída de críticas e cobrança, portanto, de alguma forma, do controle social sobre as atividades do Executivo. ${ }^{8}$

\section{Conselhos gestores em Teresina}

A promulgação da Constituição de 1988, conquistada através da pressão da sociedade civil, trouxe uma alteração nas características do federalismo brasileiro que, dentre outras, modificou o sentido da participação, estabelecendo como diretriz para as ações governa-

8. No contexto do projeto ainda serão observadas as experiências dos conselhos escolares, da área de habitação e do orçamento popular. Estamos igualmente analisando $0 \mathrm{im}$ pacto fiscal da descentralização sobre as contas da Prefeitura M unicipal de Teresina (PMT), no período que vai de 1992 a 2001 mentais a descentralização político-administrativa e a participação da sociedade civil por meio de organizações representativas na formulação e no controle de políticas públicas. A concretização dessa mudança ocorreu via criação e implementação dos consel hos gestores nas três esferas federativas: U nião, estados e municípios.

Essa nova institucional idade, que pretende transferir responsabilidades e atribuições ao poder local, passa a ser gerida segundo uma distribuição de funções entre governo federal, com papel de financiador e normatizador, e os municípios, com papel de formulador executor das políticas no plano local. Esse modelo institucional favorece a municipalização dos serviços, cabendo aos estados o papel de auxiliar em situações nas quais os municípios não possam desempenhar a contento suas funções. Nesse processo de redimensionamento de poderes, reserva-se posição estratégica para os grupos organizados da sociedade civil. Os consel hos gestores seriam, assim, emblemáticos no novo modelo de gestão participativa, constituindo recurso central no processo de transformações do sistema político-governamental brasileiro.

\subsection{O Conselho M unicipal de Assistência Social (CMAS)}

À medida que a assistência social ganha status de política pública e, portanto, torna-se integrante da seguridade social não-contributiva, regulamentada pela L ei Federal $n^{\circ} 8.742$, de 7 de dezembro de 1993, a chamada L ei Orgânica de Assistência Social (Loas) estabelece que, para o repasse de fundos do governo federal aos municípios, faz-se necessária a comprovação da efetiva criação e do funcionamento do Conselho M unicipal deA ssistência Social. N esse sentido, a assistência social, como direito do cidadão e dever do Estado, passa a ser realizada por um conjunto integrado de ações da iniciativa pública e da sociedade civil, para garantir os mínimos sociais à população.

De modo a cumprir as determinações expressas na Loas, a Prefeitura M unicipal de Teresina ( $\mathrm{PI}$ ) sancionou a L ei $\mathrm{n}^{\circ} 2.456$, que cria o Conselho M unicipal de Assistência Social 
(CM A S), e o Decreto $n^{0} 3.167$, que estabelece - Fundo M unicipal de Assistência Social (FMAS), em 18 de janeiro de 1996 e 18 de setembro de 1996, respectivamente. Segundo consta na primeira ata, "aos quatorze dias do mês de fevereiro do corrente ano, uma ' comissão de habilitação', constituída por servidores da prefeitura desse município, reuniu-se para definir o processo de eleição dos representantes das entidades não governamentais", que veio a ocorrer em 29/02/1996. O CMAS teve seus membros empossados em 5 de março daquele ano, e a primeira reunião extraordinária foi real izada no dia seguinte. ${ }^{9}$

0 conselho conta com regimento interno próprio, que data de março de 1996, aprovado em 24 de abril do mesmo ano. 0 referido documento, em consonância com a Lei de Criação do Consel ho M unicipal de A ssistência Social, apresenta diretrizes de procedimentos, bem como discorre categoricamente sobre a sua finalidade, competências, composição, organização e funcionamento desse conselho.

No papel de órgão deliberativo de caráter permanente e âmbito municipal, o CM A S tem sido responsável pela coordenação da política municipal de assistência social. Dentre as suas principais competências, destacamos: deliberar e definir as prioridades da política de assistência social; atuar na formulação de estratégias e controle da execução da política de assistência social; propor e acompanhar critérios para a programação e para as execuções financeiras e orçamentárias do Fundo M unicipal de A ssistência Social e fiscalizar a movimentação e a aplicação dos recursos; aprovar critérios de qualidade para o funcionamento dos serviços de assistência social públicos e privados no âmbito municipal; acompanhar, avaliar e fiscalizar os serviços de assistência prestados à população pelos órgãos, entidades públicas e privadas no município; aprovar critérios para a cel ebração de contratos ou convêni ss entre o setor público e as entidades privadas que prestam serviços

9. 0 conselho vem se reunind normalmente desde 0 dia 10 de abril de 1996, quando da p meira reunião ordinária. Tais reuniões, de caráter ordinário, bcorrem uma vez por mês, e aquelas de caráter extraordiná io ocorrem mediante convocação de seu presidente ou un terço de seus membros, observando o prazo de cinco dia para sua realização. de assistência social no âmbito municipal; elaborar e aprovar seu regimento interno; propor a formulação de estudos e pesquisas com vistas a identificar a realidade socioeconômica do município; cadastrar entidades e organizações que prestam serviços de assistência social no âmbito municipal etc.

Tendo em vista que os consel hos gestores devem ser compostos por representantes da sociedade civil e do governo, no caso do CM AS de Teresina (PI), cada um desses segmentos conta com sete membros e seus respectivos suplentes, com mandato de dois anos. ${ }^{10} \mathrm{No}$ entanto, há uma particularidade na estrutura do conselho em análise, que difere daquela observada no Consel ho M unicipal da Criança e do A dolescente (CM DCA), no que se refere à representação da sociedade civil, que está subdi vidida em três categorias: 1) representantes dos prestadores de serviço (representante de entidade de atendimento a infância e adolescência, representante de entidade de atendimento a deficientes e representante de entidade de atendimento à família); 2) usuários (representante das entidades ou associações comunitárias, representante dos sindicatos e entidades de trabalhos, representante de associações de idosos), e 3) profissionais da área de assistência social, escolhidos em foro próprio, através de el eição sob fiscal ização do M inistério Público.

No que tange à organização do CM AS, ele apresenta uma diretoria composta pelo presidente, vice-presidente e secretários, escolhidos dentre seus membros por processo el etivo para cumprirem mandato de um ano, sendo permitida uma recondução. Dispõe ainda de uma equipe técnica e administrativa, formada por servidores municipais para cumprir funções designadas pelo CMAS, bem como um secretário executivo, designado pelo referido consel ho, com base na indicação apresentada pel o titular da Secretaria M unicipal do Trabalho e de A ssistência Social.

10. A representação do governo, nomeada pelo Poder Executivo Municipal, apresenta a seguinte composição: representante da Secretaria M unicipal do Trabalho e de Assistência Social; 2) representante da Secretaria M unicipal de Educação e Cultura; 3) representante da Secretaria M unicipal de Saúde; 4) representante da Secretaria M unicipal de Indústria e Comércio; 5) representante da Secretaria M unicipal de Planejamento e Coordenação Geral; 6) representante da Secretaria M unicipal da Criança e do Adolescente; 7) representante da Secretaria Municipal de Finanças. 
2.2. O Conselho M unicipal dos Direitos da Criança e do Adolescente de Teresina (CM DCAT)

No que concerne às políticas destinadas à proteção da criança e do adolescente, foi promulgada a L ei 8.069, de 13 de julho de 1990, mais comumente conhecida como o Estatuto da Criança e do A dolescente (ECA ), que trata, nos artigos 86 e 88, do processo de descentralização, bem como das diretrizes da política de atendimento à área infanto-juvenil, referindo-se à criação de conselhos municipais, estaduais e nacionais dos direitos da criança e do adolescente.

A ssim sendo, os conselhos gestores tornaram-se esferas públicas institucionalizadas de deliberação, proposição e controle das ações governamentais, regulamentados por leis federais, podendo ser criados por meio de leis estaduais e municipais, como o Consel ho M unicipal dos Direitos da Criança e do A dolescente de Teresina (CM DCAT).

Esse conselho é a instância local deliberativa e controladora das políticas destinadas à criança e ao adolescente, criado pela L ei Orgânica do M unicípio, art. 237, e L ei M unicipal $n^{\circ}$ 2.052, de 6 de janeiro de 1991. A implantação desse conselho, como a de outros da capital piauiense, foi precedida de conflitos entre a sociedade civil eo governo. Segundo depoimento coletado, ${ }^{11}$ a instalação do conselho não ocorreu no momento de sua criação por "falta de vontade política do prefeito municipal da época", tendose recorrido a uma ação judicial, impetrada pela Federação das A ssociações de M oradores do Estado do Piauí (Famepi), para ter finalmente efetivado o seu funcionamento no ano de 1992.

A primei ra reunião foi realizada em caráter extraordinário em 17 de dezembro de 1992, cuja pauta foi a eleição da diretoria do consel ho. A tualmente, essa diretoria é composta pelo presidente, vice-presidente, $1^{\circ}$ e $2^{\circ}$ secretários, $1^{\circ}$ e $2^{\circ}$ tesoureiros, tendo havido mudanças em relação à primeira diretoria, que não tinha as funções de vice-presidente e $2^{\circ}$ tesoureiro.

11. A análise a que se está referindo foi realizada nos dois conselhos, englobando uma série de entrevistas semiestruturadas com os representantes da sociedade civil, bem como análise dos documentos referentes à vida institucional de ambos os conselhos.
As reuniões seguintes foram realizadas com vistas à estruturação interna, tendo sido iniciada com a escol ha da diretoria. Seguiu-se, então, a elaboração - através de uma comissão - do regimento interno. A lém da diretoria, o regimento determinou a criação de três comissões de trabalho ${ }^{12}$ destinadas a executar ações deliberadas nas reuniões.

No que diz respeito à composição do conselho, ${ }^{13}$ é respeitado o princípio da paridade. São 16 membros ef etivos e 16 suplentes, oi to conseIheiros e seus respectivos suplentes nomeados pelo Poder Executivo M unicipal, pertencentes às áreas de educação, saúde, lazer e planejamento, e oito consel heiros também com seus suplentes, indicados pela sociedade civil, através de entidades ou organizações não-governamentais. ${ }^{14} \mathrm{D}$ e acordo com o regimento interno, o número de representantes pode ser alterado, desde que seja respeitado o princípio da paridade.

\subsection{Dilemas da participação da sociedade civil nos consel hos gestores}

0 primeiro destaque do ponto de vista desta análise é a constatação do papel das organizações não-governamentais (ONGs) na assunção de funções de caráter social antes exercidas pelo Estado, promovendo uma reconstrução da realidade social e dos instrumentos utilizados para responder às demandas da população. N esse sentido, como nos lembra N unes (1996),

\footnotetext{
12. Tais comissões são: Comissão de Avaliação de Solicitação de Registro e A companhamento a Entidades e Casas de Serviços; Comissão de Avaliação e A companhamento de Programas e Projetos, e Comissão de Garantia de Direitos e Comunicação. As funções dessas comissões estão presentes no regimento interno do CMDCAT.

13. Realizamos entrevistas com representantes das ONGs, dentre titulares e suplentes, incluindo um ex-conselheiro, por considerarmos que sua contribuição seria de grande importância, uma vez que atuou durante oito anos no CMDCAT.

14. Esta é a relação de entidades representativas da sociedade civil no CMDCAT, desde sua criação em 1992: 1) M ovimento Nacional de Meninos e M eninas de Rua (MNMMR); 2) Pastoral do Menor; 3) Pastoral da Criança; 4) Ordem dos Advogados do Brasil - Seção Piauí $(O A B) ; 5)$ Conselho Regional de Serviço Social (Cress); 6) Sindicato dos TrabaIhadores em Educação (Sinte/PI); 7) Federação das A ssociações de M oradores e Consel hos Comunitários (FAM CC), e 8) Federação das A ssociações de M oradores do Estado do Piauí (Famepi).
} 
a discussão da descentralização vem permeada pela questão da reforma do Estado e do redesenho de sua inserção do ponto de vista dos serviços sociais. A ssim, à medida que transfere atribuições às entidades não-governamentais, repassa também fundos para viabilização de programas e projetos destinados à área social. Tais recursos podem ser transferidos aos órgãos governamentais e não-governamentais após avaliação e aprovação dos projetos submetidos à análise.

A alocação dos recursos tem sido questionada no Conselho de Assistência Social (CMAS), tendo em vista a natureza das entidades que vêm sendo contempladas com tais benefícios. 0 discurso dos conselheiros entrevistados aponta para a existência de categorias variadas de entidades neste município, que se distanciam ou se aproximam da proposta de promoção do desenvolvimento e estruturação da comunidade local, com registro no referido conselho. Sendo assim, a forma como se tem realizado a distribuição de recursos para a assistência social, muitas vezes com base em critérios políticos e clientelistas, constitui uma das principais insatisfações reveladas pelos membros desse conselho, que ora responsabilizam o próprio conselho por ser ineficiente na função de cadastrar entidades, pois não realizaria avaliação sistemática e imparcial no processo de obtenção de registro, ora transferem a crítica ao desenho da legislação.

$\mathrm{Na}$ área da criança e do adolescente, constatamos uma limitação na distribuição de recursos às entidades não-governamentais. Durante as entrevistas realizadas, percebeu-se a ausência ingente de informações sobre o Fundo M unicipal dos Direitos da Criança e do A dolescente de Teresina (Fumcad). Visivelmente os consel heiros não conseguem identificar para onde os projetos devem ser enviados, a fim de obter recursos. A través dos depoimentos dos consel heiros das ONGs, reconhecemos um fato curioso. M esmo sendo possível às ONGs com assento no CMDCAT elaborarem projetos visando aos recursos do fundo, há registro de poucas entidades que apresentaram projetos e foram beneficiadas, sendo os recursos advindos do Programa Criança Esperança. Diante disso, al egaram que os projetos não são apresentados por falta de conhecimento para elaboração, sendo os órgãos governamentais sempre os grandes beneficiados.

No que diz respeito aos recursos, temos a primei ra constatação relativamente ao controle do Executivo municipal sobre o funcionamento dos dois consel hos em análise. Primeiramente, verifica-se na assistência social o controle via credenciamento das entidades que devem receber recursos do orçamento municipal. Depois, a fal ta de informação e o despreparo dos representantes da sociedade civil na área da criança levam a um monopólio da utilização dos recursos do Fumcad por parte das organizações governamentais.

Cabe, a partir desta observação, perceber como a sociedade civil se faz representar em cada uma dessas arenas, analisando o processo de constituição de suas "bancadas representativas".

Como consta no regulamento do CMAS, os representantes da sociedade civil devem ser escolhidos por eleição. De fato, foi constatada a existência de registros que confirmam a realização de eleições nesse conselho para escolha dos seus membros. Entretanto, conforme 0 depoimento de al guns consel heiros entrevistados, o processo el eitoral não é muito "claro", ou seja, não tem regras bem definidas:

No nosso caso, fomos convocados para participar de uma reunião no CM A S. Lá, foi feito o convite para a nossa entidade concorrer a uma vaga no conselho. Parece que as entidades convidadas para participar da el eição são aquelas que se encontram em situação regular, e que atendem à Lei do Terceiro Setor. Esta já é a segunda vez que a nossa entidade é convocada, mas não sei dizer exatamente por quê. ${ }^{15}$

M as os discursos acerca dos meios pelos quais as entidades que representam obtiveram assento no CMAS não foram homogêneos. A lguns representantes ressaltaram a interferência do poder público, mesmo que indiretamente, no processo eleitoral. A firmaram que "existem entidades que estabel ecem conchavos

15. Os extratos dos depoimentos obtidos durante o trabalho de pesquisa seguem aqui sem identificação de seus autores, como meio de preservação de suas identidades. 
com políticos a fim de ganhar visibilidade eserem indicadas para fazer parte do conselho". Não menos surpreendente foi a declaração de um dos membros de que "existe caso de entidade que não passou pelo processo eleitoral". A entidade havia sido "simplesmente" integrada a esse consel ho. 0 próprio CM A S havia concedido a essa entidade o direito de se fazer representar, mesmo não tendo sido submetida ao processo el etivo que caracteriza os termos de regulamentação dos consel hos gestores.

Quando a questão da representação é contemplada do ponto de vista do CMDCAT, merece destaque o fato de que os membros das ON G s que se fazem presentes naquela instância não passam por um processo de escolha entre seus membros. $\mathrm{Na}$ realidade, "[...] parte dos componentes dos diversos consel hos é indicada por suas respectivas entidades, mas nem sempre por suas assembléias-gerais [...]" (Teixeira, 2001, p. 139). No CM DCAT, todas as ONGs têm seus representantes indicados sem aprovação de uma assembléia geral, conforme consta no regimento interno aprovado pel os membros desse consel ho, seguindo critérios como: disponibilidade, identificação com a causa e melhor capacidade de representar a entidade.

Contudo, não é apenas o processo de escoIha de representantes que apresenta problemas, seja quanto à escolha das entidades, seja quanto à escolha de seus representantes. Em ambos os conselhos aqui em tela, o prazo legal de mandato de sua representação, de maneira freqüente, é excedido sem que se viabilizem novas escolhas e/ou indicações. ${ }^{16}$ Tal fato ocorre tanto no que diz respeito aos representantes do governo, quanto aos da sociedade civil.

Outro dado curioso é a permuta de al guns representantes em posições variadas nos dois conselhos. Ou seja, ao invés de haver uma substituição do conselheiro de modo que seus membros sejam, de fato, renovados, tem-se apenas alteradas suas posições. No CM AS, verificamos a permanência de dois membros do governo desde a sua criação (1996). N o que se

16. No CMDCAT, de acordo com o seu regimento interno, 0 mandato seria de dois anos, podendo ser renovado apenas uma única vez. Todavia, foi possível identificar o caso de um ex-conselheiro que ingressou durante a criação em 1992 e permaneceu até o final do ano 2000. refere à permuta dos representantes desse conselho, constatou-se que um dos seus membros, em dois mandatos, foi suplente do secretário municipal do Trabalho e Assistência Social e, em seu terceiro mandato consecutivo, passou a ser suplente da secretária municipal da Criança e do A dolescente. Quanto aos representantes da soci edade civil, foi constatada a permanência de um dos membros das entidades com representatividade no CM A S desde 1996.

Foi possível observar, também, que a estrutura do CMAS apresenta alguns desfalques em sua composição. Enquanto esse conseIho conta com quatorze representantes do governo (sete titulares e sete suplentes), em concordância com a legislação, do lado da sociedade civil, tem apenas onze membros (sete titulares e quatro suplentes), segundo consta no Decreto $n^{0} 4.407$, de 15 de junho de 2000, que nomeia os membros integrantes da instituição com mandato de dois anos (biênio 2000/2002). Outra observação a ser feita refere-se à representação dos usuários: constatamos a sub-representação, no sentido que as vagas destinadas a essa categoria são ocupadas por membros de entidades nãogovernamentais, de modo que "o grande ausente nos conselhos é, sobretudo, o sujeito social alvo das políticas públicas" (Raichelis, 2000, p. 252). Trazer esses indivíduos demandantes de direitos para os espaços de decisões das políticas públicas tem sido um grande desafio.

Novo aspecto a chamar atenção e despertar reflexão sobre a representatividade é atinente à ausência de critérios mais rigorosos adotados pelas entidades quando da indicação de seus representantes. A situação que melhor evidencia essa falta de rigor é o caso de um conselheiro que, num mandato, representou uma entidade governamental e, num outro, uma ONG. No que tange à questão, são os próprios consel heiros e al gumas entidades que estão a indicar esse fator como um dos responsáveis pel o questionamento da legitimidade da participação nos consel hos.

0 que se nota, então, é a debilidade da própria institucionalização desses conselhos, cujas práticas cotidianas muitas vezes ferem os seus regimentos internos, ou terminam por trazer à tona sinais de que a sobrevivência dessas instâncias, ao menos no município de Teresina, está comprometida pela pouca participação da 
população, constatação que pode ser confirmada por fatos como as trocas de posição, extrapolações de mandato e até mesmo mudança de natureza funcional da representação por parte de um mesmo indivíduo.

A liado a esses, estão os problemas diversos que dificultam a representatividade e a paridade. $\mathrm{N}$ a concepção de Gohn (2000), "os problemas decorrem da não-existência de critérios que garantam uma efetiva igual dade de condições entre os participantes" (2000, p. 19). A paridade não se restringe à questão numérica. A desigualdade no acesso à informação altera os efeitos programados na proposta de inserção da sociedade civil no processo de elaboração e gestão das políticas públicas.

Em geral, os membros do governo têm acesso às informações, dispõem de infraestrutura de suporte admini strativo, assim como estão habituados com a linguagem tecnocrática. A o passo que os representantes da sociedade civil enfrentam inúmeras dificuldades, desde a fal ta de cursos de capacitação até disponibilidade de tempo para exercer suas funções como membros do conselho. Os representantes do governo exercem suas atividades de consel heiro durante seu período de expediente de trabalho normal/remunerado; os da sociedade civil precisam conciliar seus trabal hos às tarefas do conselho.

Nos depoimentos da maioria dos entrevistados no CM DCAT, seus membros utilizam 0 argumento da pouca disponibilidade de tempo como justificativa para a ausência nas reuniões e nas atividades de responsabilidade desse conselho. A o contrário, no CMAS, foi difícil reconhecer descontentamento quanto à disponibilidade de tempo para participar das atividades, embora membros desse consel ho tenham confessado que um dos representantes da sociedade civil já esteve afastado do cargo de consel heiro em razão da indisponibilidade de tempo.

Porém, no que se refere às oportunidades de melhorar a performance dos conselheiros, foram intensos os protestos dos representantes nos dois conselhos:

M uitos conselheiros têm dificuldades de compreender os assuntos tratados nas reuniões, isso faz com que poucos se manifestem.
Preferem se manter calados nas discussões. Certamente, se houvesse mais oportunidades de discutir as leis, normas, termos técnicos etc., poderíamos entender melhor as questões discutidas e contribuir mais na análise dos processos. (Representante da sociedade civil no CMAS)

As OGs têm um grau de informação técnica maior que as $0 \mathrm{NGs}$, entendem mais sobre gestão porque diariamente estão em contato com esse tipo de conhecimento, nós não. As informações que levamos para o consel ho são de vivência nos movimentos. (R epresentante da sociedade civil no CM DCAT)

Os assuntos colocados nas reuniões muitas vezes não são compreensíveis porque nós não temos noção das leis, então é complicado falar de uma coisa que não se conhece. As ONGs ficam em desvantagem por falta de informação. (Representante da sociedade civil no CM DCAT)

Poucos são os cursos de capacitação oferecidos para os membros dos consel hos. $E$, quando ocorrem, são restritos a uma parcela reduzida de seus membros. A Iguns dos representantes do CMAS sequer tinham conhecimento da ocorrência desses cursos ao longo de sua participação no referido conselho, e a maioria dos entrevistados declarou não receber orientações suficientes para o cumprimento de suas funções, e tampouco para o acompanhamento dos assuntos em pauta nas reuniões.

Sendo assim, as diferentes concepções e atribuições que são delegadas aos conselhos gestores levam-nos a questionar a sua atuação como supostos instrumentos de transformação social, pelo menos no queérelativo ao município de Teresina, nas áreas de política que estamos analisando.

Dentre as várias questões implícitas no atual debate, tem-se discutido a operacionalidade desses consel hos sob a forma em que vêm sendo implantados. Se, por um lado, al guns dos conseIheiros entrevistados no CM A S declararam que não se sentem coagidos para deliberar e têm autonomia diante do poder local, por outro, 0 discurso contundente de outros membros do mesmo conselho constitui indícios dos seus limites: 
Qual quer oposição do conselho frente ao poder local é desconsiderada. A politicagem interfere no trabal ho que o CMAS deveria realmente desenvolver. A interferência do poder público se reflete até mesmo nos processos de solicitação de registro das entidades. Como no caso de uma entidade que foi visitada e a gente sabe da credibilidade e presteza dos seus serviços, mas, como não faz parte do esquema político, encontrou enormes dificuldades para obter registro no CMAS, para que pudesse solicitar o título de filantropia junto ao CNAS e estar apta para receber benefício. Essas são as atitudes daqueles membros que seguem as ordens do poder local. E as decisões são concentradas nas mãos desses membros do conselho, de acordo com os interesses governamentais. Eles decidem. Dessa forma, como a gente pode influenciar no poder público?

A vulnerabilidade dos representantes da sociedade civil em face das dificuldades que enfrentam tem causado desânimo nesses membros do CM A S, a ponto de duvidarem da própria "funcionabilidade" desse conselho. N os termos de um dos seus representantes: "Da forma que este consel ho se apresenta, tem sido um conseIho de fachada, sem qual quer funcionabilidade. As decisões aqui tomadas são decisões do governo".

U m outro aspecto preocupante que merece destaque por estar relacionado à atuação dos conselheiros, desta feita no CMDCAT, diz respeito à formulação e ao controle de políticas públicas. A través das fontes pesquisadas, não foi possível visualizarmos essa relação, diante disso, questionamos: como se dá a partici pação no CMDCAT, já que as funções a serem desenvolvidas não estão sendo realizadas por completo? Podemos afirmar que a participação tem suas limitações e está direcionada com grande ênfase a questões burocráticas, tais como: participar de reuniões, analisar projetos e fiscalizar entidades.

\section{Considerações finais}

A pergunta que orientou toda a nossa análise diz respeito às condições de mudança social propiciadas pelo modelo de descentral ização de políticas públicas adotado no país na década de 1990. Segundo os dados da análise dos consel hos gestores do município de Teresina, é possível perceber que, se há condições de essas mudanças se processarem, el as ainda estão muito além do alcance de nosso entendimento.

Três ordens de problemas apareceram de maneira mais concreta. 0 primeiro diz respeito ao controle que o Executivo municipal exerce sobre o funcionamento desses conselhos, dando ênfase a pautas de seu interesse em um caso e, no outro, monopolizando o acesso a recursos do fundo público, em parte também graças à desinformação dos representantes da sociedade civil, que, no caso do Consel ho da Criança e do A dolescente de Teresina, tem uma grande representação de entidades ligadas à atuação da Igreja Católica.

0 segundo problema diz respeito à institucionalização desses conselhos, tanto no que é relativo às suas práticas cotidianas, até mesmo na simples incapacidade de manter atualizados os registros das reuniões, passando pelas violações às regras de funcionamento, no que tange à observação dos mandatos de seus representantes, e chegando ao problema da representatividade e legitimidade dessa mesma representação, que reconhece o seu despreparo para participar das discussões mais técnicas que lá deveriam acontecer.

Finalmente, surgem os discursos de conseIheiros que se preocupam com o que chamam de funcionabilidade dessas instâncias que, esvaziadas pela presença de representantes governamentais, muitas vezes sem densidade política, vítimas do poder da agenda do Executivo municipal e envoltas em discussões puramente burocráticas de registro de entidades, prestações de conta e análise de projetos já prontos, terminam por levantar a desconfiança de que, efetivamente, não têm cumprido qualquer papel de maior relevância no contexto das políticas públicas municipais.

Este diagnóstico não é novo, muito menos exclusivo do município de Teresina, pois tem sido encontrado em várias outras unidades do país. $M$ as nos al erta para o fato de que, em determinados contextos de desigual dade social, baixo nível de escolaridade e tradição política hierárquica, assimétrica e vertical, as relações Estado e sociedade civil podem ser interpretadas sob, pelo menos, duas óticas. A primeira, apostando 
em conceitos como projeto político e hegemonia, renova as esperanças no modelo e alerta para os limites e possibilidades dessa participação (Dagnino, 2002). A segunda percebe que talvez se esteja indo longe demais com tais esperanças e que, no contexto de um federalismo como o brasileiro, a descentralização na realidade só proporciona frutos àqueles que já têm recursos financeiros, de informação e organização, fazendo valer a máxima: "a quem pode, - poder, a quem não pode, a participação" (Boschi, 1999, p. 683).

Em regiões como o Nordeste e estados como o Piauí, essas questões são fundamentais, porque os riscos de manter-se à margem dos processos mais gerais de desenvolvimento, de certa maneira, têm sido até agora os únicos que realmente contam.

\footnotetext{
A bstract: This paper elaborates on the issues brought up by the process of decentralization of public policies based on the empirical cata related to the city of Teresina, PI, where two research analyses have been performed to evaluate the functional aspects and the participation of the civil society in two municipal cormittees: "social assistance" and "child and teenager." It is possible to infer from the information captured in previous surveys that the participation of civil society in these two city comittees is very limited and restricted. The activities and decisions taken by these institutions have very little effect (if any) in the mainstream public policies enforced by the city govermment. In fact, the scope of their activities is reduced to lareaucratic tasks such as providing credentials to nongovermental organizations that are pursuing philanthropic status.
}

K ey-words: decentralization, public policies, social participation, municipal comittees.

\section{Referências}

A BU -EL - HA J, J aw dat. O debate em torno do capital social: uma revisão crítica. Bi B - R evista Brasileira de Informação Bibliográfica em Ciências Sociais. Rio deJ aneiro, n. 47, 1999. p. 65-79.

A L M EIDA, M aria H. T. Federalismo, democracia e governo no Brasil: Idéias, hipóteses e evidências. BiB - Revista Brasileira de Informação Bibliográfica em Ciências Sociais. Rio de Janeiro, n. 51, 2001. p. 13-34.

A RRETCHE, M arta. Estado federativo e políticas sociais: determinantes da descentralização. São Paulo/Rio de J aneiro: Fapesp; Revan, 2000.
Políticas sociais no B rasil: descentralização em um Estado federativo. Revista Brasileira de Ciências Sociais, v. 14, n. 40, jun./1999. p. 111-141. BOSCHI, Renato. Descentralização, clientelismo e capital social na governança urbana: comparando B el o H orizonte e Salvador. D ados. Rio de J aneiro, v. 42, n. 4, 1999. p. 655-690.

BRA SIL, Constituição (1988). Constituição da República $\mathrm{F}$ ederativa do Brasil. Brasília, DF: Senado, 1988.

BRA SIL. Lei no 13 de julho de 1990. Dispõe sobre o Estatuto da Criança e do A dolescente e dá outras providências, 2000.

BRAV O, M aria Inês Souza \& PEREIRA, PotyaraA. P. (Orgs.). Política social e democracia. São Paulo: Cortez, 2001.

CAM POS, Edval B ernardino \& M A CIEL, Carlos A lberto B atista. Conselhos paritários: 0 enigma da participação e da construção da democracia. Serviço Social \& Sociedade, ano XVIII, n. 55, 1997.

COÊLHO, A ilta Barros de Souza Ramos. Política de proteção à infância e adolescência e descentralização. Serviço Social \& Sociedade, ano XX, n. 60, 1999.

COELHO, Vera et all. Política social: o que podemos esperar da participação? Paper apresentado no $3^{\circ}$ Encontro A nual da A BCP, Niterói, julho de 2002, mimeo.

DAGNINO, Evelina. Sociedade civil e espaços públicos no Brasil. São Paulo: Paz eTerra, 2002.

DIAS, Márcia Ribeiro. Sob o signo da vontade popular. 0 orçamento participativo e o dilema da Câmara M unicipal de Porto A legre. B elo H orizonte/ Rio de Janeiro: Ed. da UFM G/luperj, 2002.

EVA NS, Peter. Development strategies across the public-private divide. Berkeley, USA : U niversity of California, 1996a, p. 1033-1037.

Government action, social capital and deveIopment: reviewing the evidence on synergy. World D evelopment, 1996b, p. 1119-1132.

FIORINA, M orris P. Extreme voices: a dark side of Civic Engagement. SKOCPOL, Theda \& FIORINA, $M$ orris $P$. Civic engagement in American democracy. Washington, DC/N ew York: Brookings Institution Press; Russell Sage Foundation, 1999. p. 395-425.

FOX, Jonathan The difficult transition from clientelism to citizen ship. World D evelopment, v. 46, 1994. p. 151-184.

. How do es civil society thicken? The political construction of social capital in rural M exico. World Development, $、 24$, n. 6, 1996. p. 1089-1103. 
GA RCIA, Claudia A parecida. Eleição do Consel ho Tutelar. J ornal de Itatiba, em 13 de agosto de 1999. GOHN, M aria da Glória. Conselhos gestores e participação sociopolítica. São Paulo: Cortez, 2001. [Q uestões de N ossa Terra, v. 84].

Conselhos gestores na política social urbana e participação popular. In: ENCONTRO ANUAL DA ANPOCS, 24, 2000, Petrópolis.

GRA N OVETTER, M ark. E conomic institutions as social constuctions: a framework for analysis. Stony B rook, NY: State U niversity of New Y ork, 1992. p. 311.

HARRISON, LawrenceE. \& HUNTINGTON, Samuel P. Culture matters: how values shape human progress. N ew York, 2000. p. 2-28.

MEDEIR OS, A ntônio J osé. 0 Piauí, hoje: processos, sujeitos e dilemas. Teresina, mimeo, 2001. $19 \mathrm{p}$.

M EL $O, M$ arcus A ndré. Estado, governo e políticas públicas. In: MICELI, Sergio (Org.). 0 que ler na ciência social brasileira (1970-1995), Ciência Política (volume III). São Paulo/Brasília: Editora Sumaré; A npocs; Capes, 1999. p. 59-99.

M ONA STERIO, L eonardo M onteiro. Capital social e crescimento econômico: mecanismos. M imeo, 2000.

NASCIM ENTO, Humberto M iranda do. Capital social no Brasil: o caso de Valente/B ahia. M imeo, 2000.

NORTH, Douglas C. Institutions, institutional change and economic performance. Universidade de Cambridge, U.S.A., 1990.

NUNES, Edson. Poder local, descentralização e democratização: um encontro difícil. São Paulo em Perspectiva. São Paulo, v. 10, n. 3, 1996. p. 32-38.

PIA UÍ. Informações municipais. Cepro, 2000.

PUTNA M , Robert D. Comunidade e democracia: a experiência da Itália moderna. Rio de aneiro: Editora Fundação Getulio Vargas, 1996. p. 77-194.

RAICHELIS, Raquel. Esfera pública e consel hos de assistência social: caminhos da construção democrática. 2. ed. São Paulo: Cortez, 2000. p. 47-122; 201270.

REIS, Fábio Wanderley. Política e políticas: a ciência política e o estudo de políticas públicas. In: M ercado e utopia: teoria política e sociedade brasileira. São Paul o: E ditora da U niversidade de São Paulo, 2000. p. 45-61.

SA NTA NA, Raimundo N. M. Novos tempos, novos conceitos: as transmutações em curso. M imeo.

SANTOS, Boaventura de S. Democratizar a democracia. Os caminhos da democracia participativa. Rio deJ aneiro: Civilização Brasileira, 2002.
SOUZA, C. \& BLUM M , M árcia. A utonomia política local: uma revisão da literatura. BiB - Revista Brasileira de Informação Bibliográfica em Ciências Sociais. Rio de Janeiro, n. 48, 1999. p. 51-67.

SOUZA, Celina. Reinventando o poder local: limites e possibilidades do federalismo e da descentralização. São Paulo em P erspectiva. São Paulo, v. 10, n. 3, 1996. p. 103-112.

. Federalismo e gasto social no B rasil: tensões étendências. Lua Nova, São Paulo, n. 52, 2001. p. 5 28.

- Coalizões políticas estaduais e ajuste fiscal. Paper apresentado no $3^{\circ}$ Encontro A nual da A BCP, Niterói, julho de 2002, mimeo.

STEPA N, A Ifred. Para uma nova análise comparativa do federalismo e da democracia: federações que restringem ou ampliam o poder do demos. Dados, Rio deJ aneiro, v. 42, n. 2, 1999. p. 197-251.

. 0 federalismo descentralizado do Brasil: aproximando o governo dos cidadãos? In: BETHELL, Leslie (O rg.). Brasil. Fardo do passado, promessa do futuro. Rio deJ aneiro: Civilização B rasileira, 2002. p. 271-303.

TEIXEIRA, Elenaldo. 0 local e o global: limites e desafios da participação cidadã. São Paulo: Cortez, 2001.

TENDLER, Judith. Social capital and the public sector: the blurred boundaries between private and public. Cambridge, M assachusetts, USA : M assachusetts Institute of Technology, 1995. p. 01-23.

Good government in the tropics. B altimore and London: The J ohns Hopkins U niversity Press, 1997.

TERESINA A A nais da II Conferência M unicipal dos Direitos da Criança e do A dolescente e Conferência Lúdica deA dolescentes, realizada em Teresina de 1 a 3 de agosto de 2001.

. Consel ho M unicipal dos Direitos da Criança $\overline{\mathrm{e}} \mathrm{do} \mathrm{A}$ dolescente. Regimento Interno. 2001.

Consel ho M unicipal de A ssistência Social . Regimento Interno. 1996.

TOCQUEVILLE, Alexis de. A democracia na América. São Paulo: Editora Itatiaia Limitada; Editora da Universidade de São Paul o, 1977. p. 11-21; 383426.

VELOSO FILHO, Fco. de Assis. A economia piauiense na segund metade do século XX. Teresina, mimeo, 2001. $5 \mathrm{p}$.

VIANNA, L uiz Wernetk. Entre duas repúblicas. Mimeo, 2000. 